\title{
PENERAPAN SMART GREENHOUSE DAN TEKNOLOGI NIRSENTUH UNTUK MENDONGKRAK PRODUKSI DAN PEMASARAN ANGGREK
}

\author{
Ari Pitoyo, Elisa Herawati, Solichatun, Nita Etikawati, Tanjung Ardo \\ Prodi Biologi, Fakultas Matematika dan Ilmu Pengetahuan Alam, Universitas Sebelas Maret
}

Email: aripitoyo@ mipa.uns.ac.id; elisahera@staff.uns.ac.id; solichatun@staff.uns.ac.id; nitaetikawati@ staff.uns.ac.id; tanjungardo@staff.uns.ac.id

\begin{abstract}
Abstrak
Pabongan Orchid adalah unit usaha mikro dibidang florikultur khususnya budidaya anggrek yang terletak di Kabupaten Karanganyar. Melalui jalinan kemitraan dengan Prodi Biologi, FMIPA, Universitas Sebelas Maret, Pabongan Orchid memperoleh teknologi pembibitan anggrek melalui teknik kultur jaringan selama dua tahun terakhir. Keberhasilan ini menjadikan Pabongan Orchid mandiri dari sisi pembibitan, serta mampu mengembangkan pemasarannya melalui diversifikasi produk. Konsekuensi dari kemajuan ini adalah, 1) kebutuhan akan kapasitas ruang penanaman anggrek yang lebih besar untuk mengimbangi laju produksi bibit, 2) kualitas ruang penanaman juga membutuhkan update teknologi agar bisa menghasilkan produk yang terkontrol dan seragam. Kegiatan pengabdian ini bertujuan menerapkan teknologi berbasis internet, yang diberikan istilah smart greenhouse dan virtual garden, untuk produksi dan pemasaran anggrek. Satu unit rumah penanaman anggrek dibangun seluas $20 \times 7 \mathrm{~m}^{2}$ dengan teknologi yang mampu menjalankan fungsi monitoring dan otomatisasi. Smart greenhouse menambah kapasitas produksi bibit sebanyak 50\%. Adapun virtual garden adalah halaman website yang menampilkan suasana kebun anggrek sedekat mungkin dengan kondisi aslinya serta bisa mengakomodasi penjualan online. Strategi pemasaran dengan teknologi nirsentuh sangat adaptif untuk menyikapi kondisi pandemi dimana kontak fisik sangat dibatasi. Dengan pendekatan teknologi tepat guna di atas, diharapkan kapasitas produksi dan pemasaran anggrek terus meningkat.
\end{abstract}

Kata Kunci: anggrek, smart greenhouse, virtual garden

\section{PENDAHULUAN}

Pabongan Orchid adalah unit usaha mikro yang bergerak disektor budidaya tanaman hias, khususnya anggrek di Kabupaten Karanganyar. Pabongan Orchid mengusahakan pembesaran anggrek dari bibit yang dibeli dari penyedia bibit yang masih berwujud tanaman didalam botol sejak tahun 2014. Bibit anggrek pada umumnya diproduksi secara masal dengan tektik kultur in vitro (vitrous $=$ gelas), sehingga dipasarkan berupa bibit botolan. Dalam kurun waktu lima tahun, Pabongan Orchid sudah bisa merasakan nilai manfaat usaha ini dan menjadi tumpuan utama sumber penghasilan. Selama masa pandemi, bisnis anggrek yang digeluti Pabongan Orchid relatif bertahan dari dampak pandemi ini dibandingkan komoditi tanaman lain yang memiliki rentang panen dan pasca panen yang singkat.

Meskipun bisnis utama yang digeluti Pabongan Orchid adalah pembesaran bibit (Gambar 1), akan tetapi satu tahun terakhir sudah mulai menginisiasi pembibitan secara mandiri dengan pendampingan dari tim P2M Prodi Biologi, Fakultas Matematika dan Ilmu Pengetahuan Alam (MIPA) (Solichatun et al, 2021). Meskipun dengan alat steriliasi dan wadah penanaman in vitro sederhana (Gambar 1c), Pabongan Orchid telah berhasil memperoleh bibit 
hasil perkecambahan biji anggrek. Melalui persilangan diperoleh ribuan biji dalam satu buah. Biji-biji ini dapat dikecambahkan dengan bantuan teknik kultur in vitro hingga menjadi bibit di dalam botol. Potensi koleksi dan kemampuan kultur in vitro menjadi modal Pabongan Orchid menuju kemandirian dalam pembibitan.

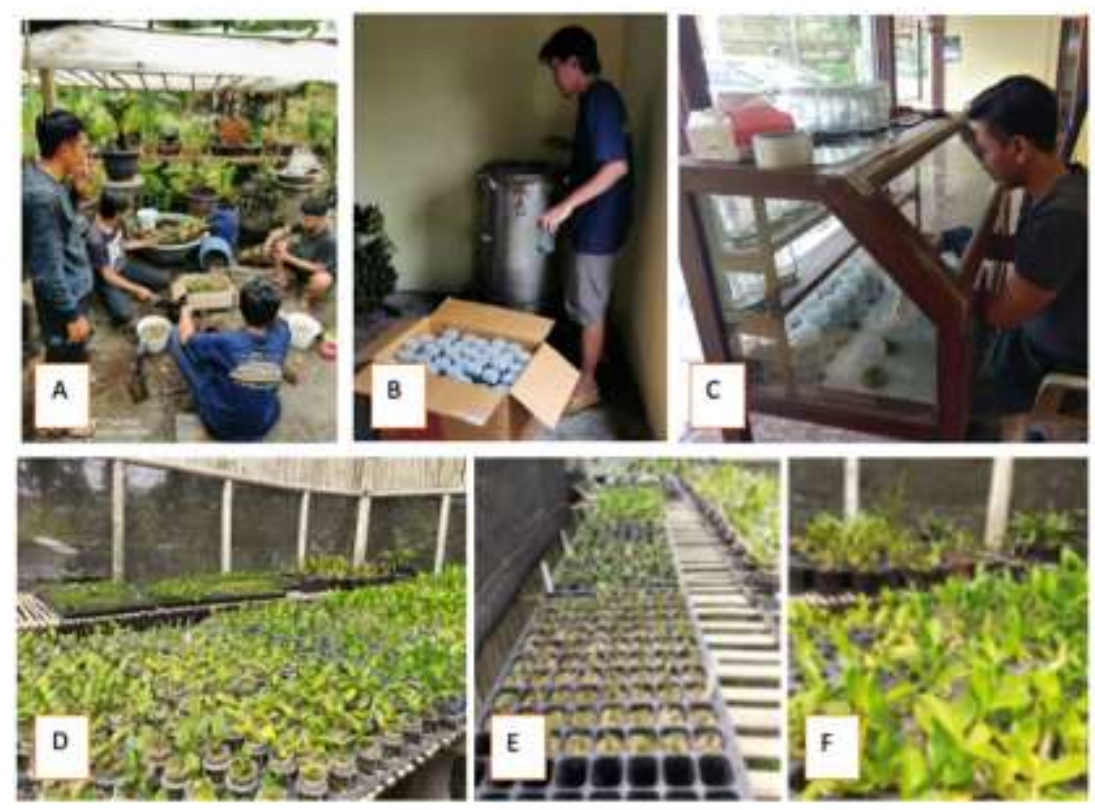

Gambar 1. Ragam aktivitas dan suasana di Pabongan Orchid. (A) Aktivitas menempelkan anggrek di media tanam; (B) sterilisasi alat dan media pembibitan; (C) penaburan biji pada enkas; (D) suasana pembesaran di rumah penanaman; (E) bibit pasca keluar botol; (F) tanaman remaja setelah satu tahun penanaman bibit.

Pabongan Orchid membesarkan bibit hibrida dan spesies yang masing-masing baru bisa dipanen minimal setelah usia satu tahun keluar botol (sekitar 18 bulan). Akan tetapi, kapasitas rumah penanaman tidak cukup menampung lebih dari 2000 bibit, sehingga panen dilakukan tiga kali pasca setahun tanam. Produk yang dijual jarang dalam kondisi berbunga, karena membutuhkan waktu lebih lama dan rumah penanaman kurang mendukung untuk pembungaan secara serempak. Volume keberhasilan pembesaran di rumah penanaman tidak lebih dari $70 \%$. Dari 6000 bibit yang ditanam baik angrek hibrida dan spesies, hanya 4000 yang berhasil dipanen. Tanaman busuk karena jamur maupun serangan hama menjadi faktor utama reduksi keberhasilan pembesaran bibit.

Produk anggrek Pabongan Orchid didistribusikan kepada pedagang eceran (reseller) maupun pengguna akhir. Konsumen utama adalah pengecer yang biasanya akan membesarkan hingga berbunga sebelum akhirnya dijual lagi. Pengguna akhir selama ini kurang tergarap karena pada umumnya lebih tertarik pada anggrek yang berbunga. Kapasitas dan kualitas rumah penanaman tampaknya sangat perlu untuk ditingkatkan.

Sistem pemasaran dilakukan secara daring (online) melalui Whatsapp dan luring (offline). Selama masa pandemi, kunjungan ke kebun atau rumah penanaman dibatasi sehingga pada awal pandemi mengalami stagnasi penjualan. Pengalihan ke penjualan daring dengan media sosial cukup mendongkrak penjualan selama masa pandemi. Bahkan terjadi peningkatan karena banyak masyarakat berada dirumah mencari aktivitas yang dapat menghibur.

Mencermati permasalahan yang dihadapi mitra, seperti belum optimalnya keberhasilan pembesaran anggrek dengan rumah penanaman yang nir 
teknologi dan stagnasi pemasaran pada saat pandemi Covid-19, maka tema yang ditetapkan dalam kegiatan ini adalah "Pemberdayaan Usaha Mikro". Adapun sasaran aspek yang akan digarap adalah "Peningkatan Kapasitas Teknologi/ Proses Produksi" dan "Teknologi Pemasaran".

Secara umum, mitra berkeinginan meningkatkan produksi dan menghasilkan produk anggrek hingga berbunga. Akan tetapi kondisi kapasitas dan kualitas rumah penanaman yang ada belum mampu mendukung tujuan tersebut (Gambar 1). Untuk memperoleh pembungaan secara seragam seringkali membutuhkan perlakuan suhu dan pencahayaan (Shibao et al, 2018; van Tongerlo et al, 2021) yang tidak bisa difasilitasi oleh rumah kaca yang masih tradisional. Penambahan fasilitas ruang penanaman juga dapat meningkatkan kapasitas produksi. Hal ini sangat penting mengingat Pabongan Orchid sudah mampu mengupayakan pembibitan secara mandiri. Rumah penanaman yang ada juga perlu difikirkan juga untuk dapat dikontrol dari jauh dan meminimalkan sentuhan sebagai konsekwensi dari upaya melawan pandemi.

Peningkatan produksi juga tidak boleh mengesampingkan bagaimana produk dapat terserap oleh konsumen, sehingga mitra merasa perlu dukungan untuk memasarkan produknya disaat pandemi dengan adanya batasan interaksi sosial. Mitra sudah berusaha beralih ke pemasaran daring

\section{METODE}

Pihak-pihak yang terlibat dalam kegiatan ini terdiri dari tim pangabdi Prodi Biologi FMIPA Universitas Sebelas Maret, mitra Pabongan Orchid, dan masyarakat Dusun Pabongan, Desa Berjo, Kecamatan Ngargoyoso, Kabupaten Karanganyar. Kegiatan ini dilaksanakan pada bulan MeiSeptember 2021 melalui tahap sosialisasi kegiatan, penerapan teknologi tepat guna (TTG), dan monitoring dan evaluasi.

Tahap sosialisasi program yaitu mengenalkan program diseminasi teknologi ke masyarakat kepada pihak Pemerintah Daerah Kabupaten Karanganyar dalam hal ini dari Bappeda. Kegiatan dengan media sosial akan tetapi perlu dilengkapi dengan pengembangan media yang dapat meningkatkan kepercayaan dan kepuasan konsumen.

Solusi dan inovasi yang ditawarkan untuk mengatasi permasalahan di atas adalah dengan fasilitas smart greenhouse (rumah kaca pintar), yaitu rumah pembesaran anggrek yang menerapkan teknologi IOT (internet of things) untuk fungsi monitoring dan otomatisasi (Azaza et al, 2016). Teknologi ini bertumpu pada sensor untuk memperoleh data parameter spesifik dari target, converter yang mengubah data dari sensor menjadi data digital, infrastruktur internet untuk transfer data digital secara jarak jauh, dan software yang dapat mengolah data dan mengeksekusi kerja dari sebuah piranti (Rayhana et al, 2020). Tim pengabdi juga mengembangkan Virtual garden, yaitu website yang dirancang untuk menghadirkan suasana kebun secara virtual. Suasana kebun diperoleh dari data yang dikumpulkan oleh sensor pada suatu pusat data. Website ini sekaligus difungsikan untuk tujuan pemajangan (display) produk secara virtual. Saat pelanggan tertarik pada salah satu obyek dalam gambar, maka ketika dipilih akan muncul sebuah jendela informasi yang berisi hal-hal yang terkait dengan obyek (misalkan nama, cara penanaman, waktu berbunga, dan sebagainya).

ini dilakukan agar kegiatan pengabdian yang diakukan dapat disinergikan dengan kegiatan pemerintah kabupaten. Kegiatan sosialisasi di tingkat pemerintah desa lebih bersifat pemberitahuan dan permohonan ijin pelaksanaan. Tahap penerapan TTG berupa beberapa rangkaian proses mulai dari instalasi alat dan sistem IOT, edukasi kepada mitra dan masyarakat sekitar tentang teknologi berbasis internet, pendampingan kepada mitra dan pembuatan Strandard Operational Procedure (SOP) seperti yang dirangkum pada Gambar 2. 


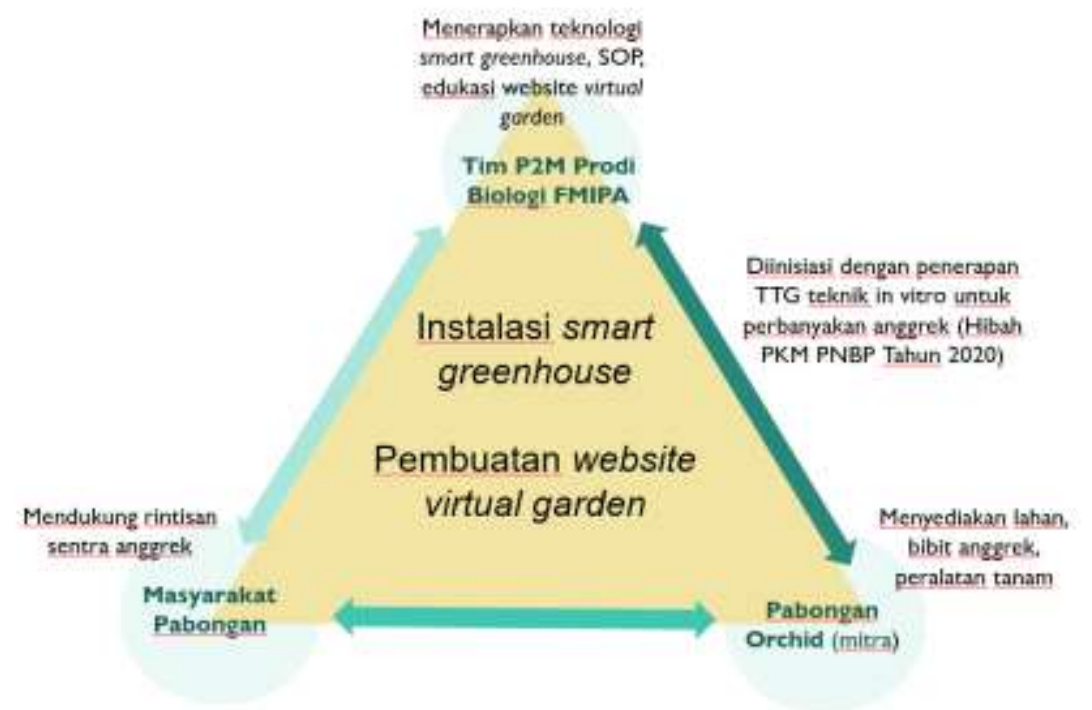

Gambar 2. Penerapan teknologi internet of things untuk peningkatan produksi dan pemasaran di Pabongan Orchid.

Evaluasi dan Monitoring dilakukan untuk mengetahui tingkat pemahaman mitra terhadap teknologi yang diaplikasikan. Refleksi seluruh kegiatan selama tahap inisiasi dan tahap pelaksanaan akan dilakukan dengan diskusi (offline maupun online) dalam tim yang diperluas dengan melibatkan kelompok tani anggrek dan pihak

\section{HASIL DAN PEMBAHASAN}

Rangkuman capaian hasil kegiatan dan dampaknya terhadap mitra ditampilkan pada Tabel 1. Satu unit smart greenhouse (Gambar 3) telah dimanfaatkan untuk pembesaran bibit-bibit anggrek. Sistem keja smart greenhouse ini dioperasikan dari jarak jauh melalui piranti komputer atau smartphone sepanjang ada koneksi intenet. Berdasarkan diskusi dengan mitra, pendekatan ini dirasa menguntungkan pada situasi pandemi karena meminimalisasi sentuhan pada obyek-obyek penanaman. Selain itu, teknologi ini juga adaptif untuk melakukan tugas harian yang tidak bisa dijadwalkan secara seragam, misalkan suatu eksekusi kerja yang sangat tergantung hasil input dari data sensor atau database lingkungan. Fungsi kontrol lingkungan meliputi kontrol suhu, aerasi, dan cahaya yang pamong. Hal ini dimaksudkan untuk mengetahui titik-titik kelemahan yang terjadi selama kegiatan diseminasi teknologi ke masyarakat ini berlangsung. Diskusi refleksi ini diharapkan menghasilkan rekomendasi perbaikan untuk pelaksanaan kegiatan sejenis di masa yang akan datang.

dapat diatur pada suhu optimal untuk mendukung pembungaan anggrek.

Upaya untuk menjadikan Pabongan Orchid sebagai rintisan sentra anggrek di Desa Berjo cukup berhasil. Pemuda sekitar yang tertarik telah bergabung untuk membantu pekerjaan memperbanyak bibit ataupun merawat anggrek. Adanya fasilitas smart greenhouse juga menjadi ajang pembelajaran lapangan (field study) oleh mahasiswa, khususnya dari UNS yang tergabung dalam kegiatan Merdeka Belajar Kampus Merdeka (MBKM). Melalui kegiatan MBKM tersebut, aktivitas mahasiswa di Pabongan Orchid direkognisi menjadi kredit mata kuliah pilihan, misalnya pada mata kuliah Orchidologi dan Fisiologi Biji. Dengan demikian, kegiatan pengabdian ini secara langsung memberi manfaat 
resiprokal baik kepada mitra pengabdi maupun instansi pelaksana. Prospek keberlanjutan kegiatan ini sangat baik. Apabila sentra anggrek Desa Bejo semakin dikenal luas, maka daerah ini berpotensi menjadi daerah wisata edukasi dan wisata hobi.

Selain smart greenhouse, website dengan konsep virtual garden (Gambar 4) juga dibuat untuk membantu pemasaran online secara intensif dalam satu athun terakhir. Website ini menampilkan produk-produk anggrek dalam wujud bibit, ataupun yang sudah berbunga. Tips-tips perawatan anggrek juga diupdate secara berkala. Website ini juga meningkatkan prestise Pabongan Orchid selain juga melayani konsultasi/ edukasi customer. Walaupun terjadi peningkatan order dan jangkauan pemasaran (Tabel 1), kendala yang dirasakan oleh mitra adalah, saat ini belum ada staf administrasi yang secara khusus bertugas mengelola website. Dengan semakin berkembangnya pemasaran online, ke depan, hal ini akan menjadi prioritas untuk dicarikan solusinya. Rekruitmen staf (warga lokal) untuk pekerjaan administrasi website membutuhkan pelatihan khusus agar mereka familiar dengan website/blog.

Tabel 1. Capaian kegiatan dan dampak program kemitraan masyarakat bagi mitra
(1) Tersedia 1 unit smart greenhouse
(2) Sistem monitoring dan otomatisasi kerja alat di rumah kaca berfungsi dan terkontrol
(3) Kapasitas produksi bibit meningkat $50 \%$
(4) Anggrek dapat tumbuh dan berkembang lebih baik dan sehat
(1) Ada website berkonsep virtual garden
(2) Peningkatan volume pemasaran anggrek sebesar $25-50 \%$
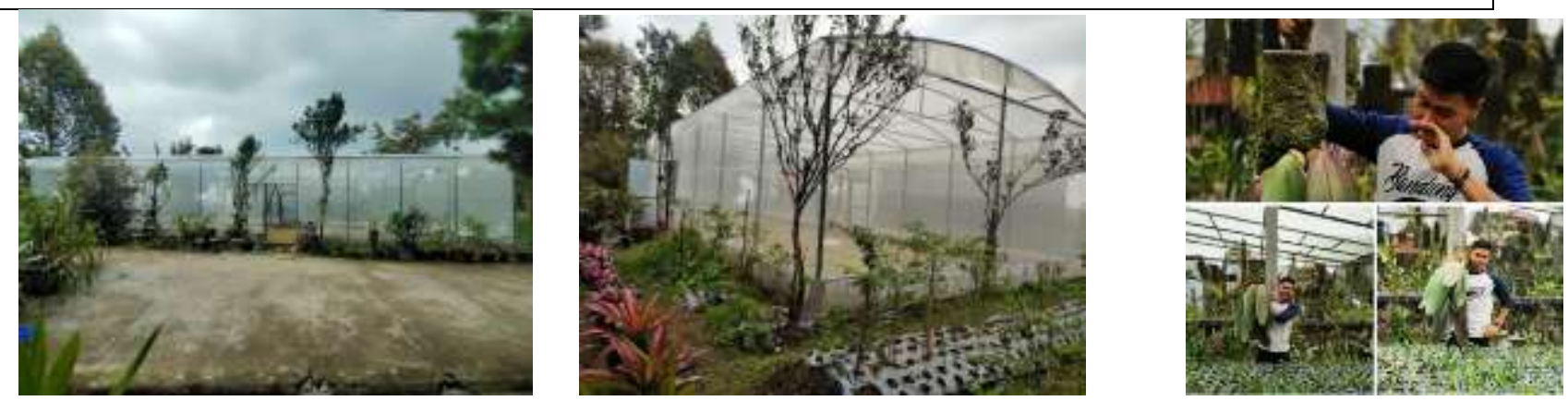

Gambar 3. Smart greenhouse seluas $20 \times 7 \mathrm{~m}^{2}$ dengan pondasi semi-permanen.

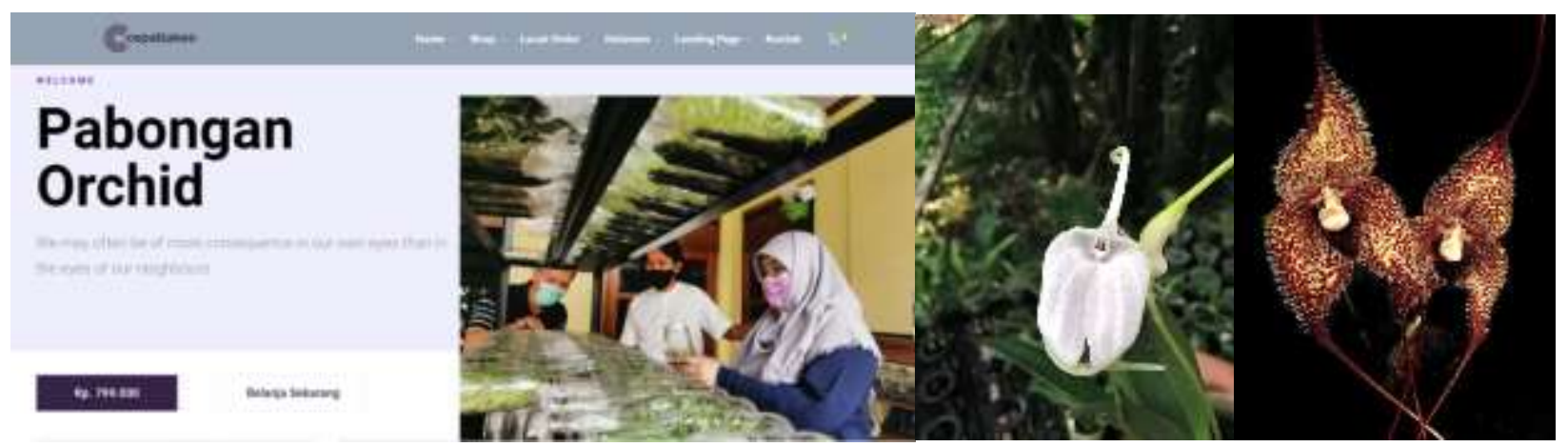

Gambar 4. Halaman depan website Pabongan Orchid dan contoh koleksi anggrek yang dijual seperti Masdevallia tovarensis (bunga putih, foto tengah) dan Dracula walisii (foto kanan). 


\section{KESIMPULAN}

Penerapan teknologi tepat guna berbasis internet berupa satu unit smart greenhouse dan wesbite virtual garden telah berhasil mendongkrak produksi dan pemasaran anggrek di Pabongan Orchid. Produksi bibit meningkat sebanyak 50\% dan diimbangi dengan keberhasilan pembesaran bibit-bibit anggrek karena kondisi lingkungan (suhu, aerasi, cahaya) yang dapat dikontrol. Pemasaran online melalui wesbite virtual garden mendapat respon yang baik, terbukti dengan animo pelanggan baru yang menunjukkan bahwa jangkauan pemasaran menjadi lebih luas. Strategi ini sangat relevan di era pandemi dimana kontak fisik dan mobilitas masyarakat harus dibatasi.

Kendala yang dihadapi adalah masih terbatasnya staf khusus untuk mengelola website. Hal ini dapat diatasi dengan rekruitmen warga lokal yang telah mendapat pelatihan teknologi informasi dan pemasaran. Potensi keberlajutan kegiatan ini sangat besar berupa, 1) pendampingan Desa Berjo sebagai sentra anggrek, 2) pemberdayaan Desa Berjo sebagai wisata edukasi atau wisata hobi berbasis florikultur.

\section{UCAPAN TERIMA KASIH}

Penulis mengucapkan terima kasih atas dukungan dan kerjasama dari Pabongan Orchid, Kemuning Orchid, dan masyarakat Desa Berjo Kabupaten Karanganyar. Program Kemitraan Masyarakat ini didanai oleh Universitas Sebelas Maret melalui Hibah PKM Non-APBN (No : 261/UN27.22/HK.07.00/2021).

\section{REFERENSI}

1. Azaza, M., Tanougast, C., Fabrizio, E., Mami, A. (2016). Smart Greenhouse Fuzzy Logic Based Control System Enhanced With Wireless Data Monitoring, ISA Transactions, vol. 61, pp 297-307, https://doi.org/10.1016/j.isatra.2015.12.006.

2. Rayhana, R., Xiao, G. and Liu, Z. (2020). Internet of Things Empowered Smart Greenhouse Farming. IEEE Journal of Radio Frequency Identification, vol. 4, no. 3, pp. 195-211, doi: 10.1109/JRFID.2020.2984391.

3. Solichatun, Pitoyo, A., Etikawati, N., Herawati, E., Ardo, T. (2020). Penerapan Teknologi Kultur Jaringan Bagi Petani Anggrek di Desa Berjo, Karanganyar. Prosiding PKM-CSR, vol 3. pp 217-223.

4. Shibao, Z., Yingjie, Y., Jiawei, L., Jiao, Q., Wei, Z., Wei, H., Hong, H. (2018). Physiological Diversity of Orchids. Plant Diversity, vol 40(4), pp. 196-208, https://doi.org/10.1016/j.pld.2018.06.003.

5. van Tongerlo, E., van Ieperen, W., Dieleman, J.A., Marcelis, L.F.M. (2021). Vegetative Traits Can Predict Flowering Quality in Phalaenopsis Orchids Despite Large Genotypic Variation in Response to Light and Temperature. PLoS ONE 16(5): e0251405. https://doi.org/10.1371/journal.pone.0251405 